\title{
Continuing Medical Education in Cardiology. Proposal for a National Program. Committee of Medical Residency and Training in Cardiology - SBC/FUNCOR
}

\author{
Bráulio Luna $\mathrm{F}^{\circ}$, Valter C. Lima, Celso Ferreira $\mathrm{F}^{\circ}$, Carlos Gun, Orlando Campos $\mathrm{F}^{\circ}$, \\ Rui Póvoa, Ângelo A. V. de Paola, Celso Ferreira
}

São Paulo, SP - Brazil

In the last decades, the evolution of knowledge has increased the volume of information in an exponential manner, particularly in the area of biomedicine, where there are 30,000 periodicals, and two million manuscripts and 17 thousand books are published annually ${ }^{1,2}$. For a cardiologist to stay abreast of this great volume of published material, it is estimated that he/she would have to read about 26 scientific manuscripts each day. This challenge plus the scarce time physicians have to read at all explains the significant development and acceptance of medical educational programs throughout the world ${ }^{3}$.

Another important aspect is the process by which physicians incorporate new knowledge into their daily practice. As recently as two decades ago, the instructions provided in medical school were used for a long period of time in a physician's life. Today, the validity period of certain diagnostic management techniques and treatment approaches gets shorter and shorter. Although the need to stay current is mandatory, this is turning into something more and more difficult to achieve ${ }^{4}$. Many studies show that even though physicians say they keep up to date by consulting books, specialized periodicals and attending congresses, in reality, what they do is consult the closest colleague ${ }^{5}$. On the other hand, to change a medical management method is not always an entirely rational process.

Some studies on the influence of continuing medical education that used the methods of clinical investigation and meta analysis have confirmed its value for updating health care professionals ${ }^{6}$. However, the global results are deceiving when the real impact obtained in clinical practice ${ }^{7,8}$ is considered. Among the innumerable strategies for updating medical knowledge, the most significant ones are the supervision of or access to prestigious specialists, usually through visits in work places. However, the strategy commonly employed by institutions dedicated to continuing medical education is still the use of combined formulas that consider the differences of interests between general clinicians and specialists $^{9}$ (table I).

The Sociedade Brasileira de Cardiologia (SBC - Brazilian Society of Cardiology) and FUNCOR (Foundation of Research and Studies in Cardiology) should decisively get involved in this question, stimulating and supporting all existing initiatives, besides contributing in a conclusive way to the organization of a national program of continuing education in cardiology. This program should consider the large regional diversity of Brazil and provide all interested cardiologists with general pathways of access to new information, updating and training.

\section{Objective}

The basic purpose of a continuing education program is to expand medical knowledge, ability and attitude to promote efficient and effective patient care ${ }^{(5,8)}$. Consequently, it is based on providing physicians with information necessary for this purpose. Therefore, the initial premise of this program is to develop permanent actions along with medical and paramedical professionals in cardiology, spreading new concepts and solidifying the ones already established, aiming at the continuing improvement of the professional and the quality of medical assistance in the specialty. To this purpose, we emphasize two initial levels that this program should consider to fit the Brazilian reality: 1) The basic program should include the practical aspects of diagnosis and treatment of the main cardiac diseases, with special emphasis on incorporating the modern advances of

\begin{tabular}{|lcc|}
\hline $\begin{array}{c}\text { Table I - Educational reasons for physicians to change medical } \\
\text { practice technique }\end{array}$ \\
\hline & Clinician (\%) & Specialist (\%) \\
\hline Scientific Periodicals & 13 & 36 \\
Press & 5 & 3 \\
Congresses and Conferences & 1 & 20 \\
Courses & 25 & 8 \\
Researches & 4 & 6 \\
Handling and treatment protocols & 6 & 2 \\
\hline
\end{tabular}

Allery LA ${ }^{9}$. 
clinical epidemiology (cardiology based on evidence) and prevention; 2) The program should complement and update cardiologists interested in specific subspecialty areas, such as Hemodynamics and Angiocardiography, Arrhythmia and Clinical Electrophysiology, Pediatric Cardiology, Heart Disease and Pregnancy, Hypertension, Ergometry and Rehabilitation, Atherosclerosis, Cardiovascular Surgery, Echocardiography, and Cardiovascular and Respiratory Physiology.

Action program - This program is based on the following assumptions: 1) To be of national comprehensiveness -Considering the difficulties inherent in a country of continental dimensions and presenting marked regional contrasts, but respecting the experiences of the local cardiac societies, including their priorities and demands;2) to emphasize prevention - approaching different cardiac diseases within strategies that give priority to primary and secondary prevention, contributing to an increase in epidemiological, pathophysiological and social comprehension of these diseases; 3) to use existing human resources Motivating the participation of regional representatives of the Brazilian Society of Cardiology (SOCESP, SOCERJ, etc.); 4) to look for effective partnerships - acting together with institutions engaged in formation and improvement of human resources, such as medical schools and research and professional qualification funding institutions $(\mathrm{CNPq}, \mathrm{CA}-$ PES, FAPESP), as well as pharmaceutical and medical equipment industries, as generating sources of funds to make feasible the projects for updating and continuing education; 5) to periodically reassess board certifications - although controversial, this question raises the need for establishing criteria for revalidation of board certification. We suggest the adoption of a model similar to the one developed by the American Medical Association (AMA), which consists of a system of credits annually accumulated, obtained through participation in congresses, courses, symposiums, scientific publications, thesis defense, etc ${ }^{(10)}$. We believe that if this system were created, it would be a great motivation for wider participation by cardiologists in the activities sponsored by the SBC and its branches, as well as a major valorization of medical updating.

\section{Tools to implement this program (table II)}

A) Permanent updating courses - Coordinated by the Scientific Commission of SBC, a Center of Studies in Cardiology would be founded. This center would systematically organize: 1) Modules consisting of topics of cardiology developed by the regional branches of SBC or by guest speakers in specific areas, aiming to establish a permanent and professional framework of courses annually available throughout Brazil. This would be done through recorded material (video rental), slides and the possibility of circulation of this material among the branches throughout the country. Simultaneously, a timetable with the courses offered at the regional branches of SBC and FUNCOR would be provided; 2) classes and interviews through cable $\mathrm{TV}$, involving hospitals and institutions with a significant number of physicians; 3) Publication of the SBC-FUNCOR Bulletin in a simple format consisting of one sheet of paper. It would be issued fortnightly and would contain relevant articles about diagnosis and treatment in cardiology. It would also provide comments of specialists on recent results of clinical trials or other types of studies with immediate implications for cardiological practice; 4) Creation of pages with abstracts of the main medical articles in cardiology on the SBC-FUNCOR site on the Internet, as well as the presentation of classes by means of slides; 5) Creation of the Service of Bibliographic Consultation in the Center of Study in Cardiology with access by telephone or Internet, providing high quality scientific information for cardiologists and population. These articles could be accessed through specific data bases, such as MEDLINE, with the survey of the original articles done by BIREME or through access to the collections of SBC-FUNCOR. The copies of the articles obtained would then be sent by FAX, e-mail or postal service at the cost price to persons interested, or for free, if financial aid were obtained with the pharmaceutical and equipment industries; 6) creation of HOT LINE in the Center of Study in Cardiology, where cardiologists from any part of Brazil could try to answer questions about diagnosis and management. A volunteer specialist would be designated weekly for this service.

B) Aiming to complement and update the information of the cardiologist in specific areas, we propose: 1) Exchanges with official institutions or those accredited with SBCFUNCOR of cardiologists interested in learning or improving in specific areas of cardiology. This would happen through paid training (grants provided by SBC-FUNCOR or other official programs) during a limited period varying from one month to one year. The candidate would commit to return to his/her original place after the end of training in order to apply and spread the acquired knowledge; 2) to sponsor visits of "itinerant teachers". This would consist of specialists traveling to a certain place for a short period of time (days or weeks) to give theoretical-practical courses about variable themes in the specialty.

Table II - Main Strategies in Continuing Medical Education (CME)

CME should prepare the professional to learn during his/her whole life not only to get acquainted with the current techniques and knowledge.

Computer era Change in the paradigm

Tools to educate

TV

e-mail

MEDLINE etc.

Electronic magazines

Courses of critical evaluation of medical literature

Specialists contact (visits, hot line)

Congresses, symposiums and refreshing courses

Ethical responsibility in the quality of medical care 


\section{Conclusion}

The current preliminary sketch intends to be a modest contribution to SBC-FUNCOR in regard to continuing medical education in cardiology. It was not our intention to totally encompass the complex problem of the development of a recurring scientific program nation wide. This enterprise, certainly necessary and deserving of distinction in every scientific and technical meeting of SBC-FUNCOR, will require a political decision with long-lasting repercussions that is also unquestionably relevant to the majority of cardiologists and patients - the most affected by the benefits.
Therefore, considering the experience that SBC-FUNCOR and its most active branches have acquired in this area, it is time to gather all efforts to offer cardiologists and Brazilian society that SBC equal to that of the highest level internationally, both in educational and professional fields.

Modern medicine requires updated information for health care professionals and good clinical judgement as well. William Osler said that medicine is an art that combines uncertainty and scientific probability. Our modest goal is to contribute to this adequate combination aiming to bring a more scientific medical practice within the reach of the Brazilian cardiologist.

\section{References}

1. Hebert PC, Tugwell PX - A reader's guide to the medical literature - an introduction. Postgrad Med J 1996; 72: 1-5.

2. Mulrow CD - Rationale for systemic reviews. BMJ 1994; 309: 597-9.

3. Haynes RB, Davis DA, McKibbon A, Tugwell P - A critical appraisal of the efficacy of continuing medical education. JAMA 1984; 251: 61-4.

4. Ramsey PG, Cardline JD, Inui TS, et al-Changes over time in the knowledge base of practice internists. JAMA 1991; 266: 1103-07.

5. Covel DG, Uman GC, Manning PR - Information needs in office practice: are they being met? Ann Intern Med 1985; 103: 596-9.

6. Davis DA, Thomson MA, Oxman AD, et al-Evidence for effectiveness of CMEA review of 50 randomized controlled trials. JAMA 1992; 268: 1111-17.
7. Wentz DK, Osteen AM, Cannon M - Continuing Medical Education Unabated Debate. JAMA 1992; 268: 1118-20.

8. Davis DA, Thomson MA, Oxman AD, et al - Changing physician performanceA systematic review of the effect of continuing medical education strategies. JAMA 1995; 274: 700-05.

9. Allery LA, Owen PA, Robling MR - Why general practitioners and consultants change their clinical practice: a critical incident study. Br Med J 1997 314: 870-4.

10. American Medical Association - Physician's Recognition Award Information Booklet. Chicago: American Medical Association, 1992. 